\title{
Development of New Cryogenic Steels for the Superconducting Magnets of the Fusion Experimental Reactor
}

\author{
Hideo NAKAJIMA, Kiyoshi YOSHIDA and Susumu SHIMAMOTO \\ Superconducting Magnet Laboratory, Division of Thermonuclear Fusion Research, Naka Fusion Research Establishment, Japan Atomic \\ Energy Research Institute, Mukaiyama, Nakamachi, Naka-gun, Ibaraki-ken, 311-02 Japan.
}

(Received on December 28, 1989; accepted in the final form on April 20, 1990)

\begin{abstract}
The Japan Atomic Energy Research Institute (JAERI) has successfully developed new cryogenic steels for the superconducting magnets of the Fusion Experimental Reactor (FER) in collaboration with 4 steel companies. JAERI required a strength-toughness combination ( $\sigma_{y}>1200 \mathrm{MPa}, K_{\mathrm{lc}}>200 \mathrm{MPa} \sqrt{\mathrm{m}}$, called JAERI box) that was beyond the capabilities of the existing austenitic stainless steels for cryogenic use. These requirements were determined from stress analyses, properties of the superconducting materials, crack propagation analyses, coil operation, etc. The new cryogenic steels were developed using tension, Charpy impact, and fracture toughness tests, step by step. The largest 4-K testing machine in the world, of maximum load $100 \mathrm{t}$, was installed at JAERI in order to evaluate the mechanical properties of large specimens and to investigate specimen size effects. The newly developed steels supplied from industrial heats $(5-50 t)$ were named "Japanese Cryogenic Steels" (JCS), and their mechanical properties satisfied requirements mentioned the above. These steels have been already used in superconducting coils, such as JAERI's Demo Poloidal Coils (DPC).

This paper reviews the development of the JCS for the superconducting magnets of the FER.
\end{abstract}

KEY WORDS: cryogenic test method; fusion reactor; high strength; high fracture toughness; liquid helium temperature; new cryogenic austenitic stainless steel; size effect; superconducting magnet.

\section{Introduction}

At present, most cryogenic structures use conventional austenitic stainless steels, such as $304 \mathrm{~L}$ or $316 \mathrm{~L}$ that were not specially developed for cryogenic use. The performances of superconducting magnets are compromised due to the limitations of such materials. Since superconducting magnets for fusion reactors experience large electromagnetic forces, high strength materials are required. The Large Coil Task (LCT), an international program conducted under the auspices of the International Energy Agency (IEA), started to explore the problem of design and construction of superconducting coils for tokamak fusion reactors in 1980.,2) Nitrogen-strengthened austenitic stainless steels were used to improve the strength of the structural materials of the LCT coils. For example, 304LN containing $0.15 \% \mathrm{~N}$ was used in the Japanese LCT coil. The yield and the ultimate tensile strengths of this material are about 800 and $1600 \mathrm{MPa}$, respectively. ${ }^{3)}$ The electromagnetic forces increase in proportion to the size of the super-conducting coil. Therefore, the stress design margin for a large coil is limited even if nitrogen-strengthened austenitic stainless steels are used. In addition, when the LCT coil was constructed, few data at liquid helium temperature $(4 \mathrm{~K})$ were available on mechanical properties of austenitic stainless steels supplied from industrial heats.

The Japan Atomic Energy Research Institute (JAERI) began to evaluate the mechanical properties of 300 -series austenitic stainless steels at $4 \mathrm{~K}$ and to develop new cryogenic steels which have high strength and toughness. First, the effect of carbon and nitrogen contents on the strength and Charpy absorbed energy of austenitic stainless steels were investigated.,4) Collaborations between JAERI and 4 Japanese steel industries were then established and the development of new cryogenic structural materials was initiated in 1982. This paper describes the requirements for structural materials, the process of materials development, the mechanical properties of new materials, and their applications.

\section{Development of Superconducting Coils for Fusion Reactors and Structural Materials}

It has been recognized that superconducting magnets technology is necessary for fusion reactors. If copper (non-superconducting) magnets are used, the electrical power consumption will be higher than the feasible range of power generation.

JAERI has been systematically developing superconducting large coils for tokamak fusion reactors. The present goal of the development is the Fusion Experimental Reactor (FER). ${ }^{5)}$ FER is the new large tokamak machine in Japan, and it supersedes the existing large tokamak called JT-60 now under experiment at JAERI's Naka Fusion Research Establishment.

Fig. 1 shows a bird's-eye view of the FER. Two groups of coils, toroidal field (TF)-œils, and poloidal 
field (PF) coils, will be used to confine the plasma which will be about $10 \mathrm{~m}$ in diameter. The TF coils confine the plasma and keep it from the surface of the vacuum chamber. The $P F$ coils, which are composed of many ring coils, induce the plasma current and stabilize the plasma ring inside the vacuum chamber. The strong magnetic field generated by these coils acts as an invisible wall to confine the hot plasma at a temperature of more than 100 million ${ }^{\circ} \mathrm{C}$.

There are several key issues in regard to the development of reliable superconducting magnets for the FER. One is the development of high strength and high toughness structural materials which can support the large magnetic forces generated by the coils. Structural materials having high strength and toughness are necessary for the TF coil cases, the conduits of forced-flow conductors, and other structures. Fig. 2 shows examples from the application of structural materials to the TF coil case, and to the conduit of a conductor. The coil case (hatched part) of the Japanese LCT coil (Fig. 2(a)) made of 304LN, weighed about $20 \mathrm{t}$, half of the weight of the entire coil. The LCT coil case is about $50 \mathrm{~mm}$ thick, whereas that of the FER will exceed $100 \mathrm{~mm}$. The conduit is $1-3 \mathrm{~mm}$ thick; it shields the supercritical helium and reinforces the conductor (Fig. 2(b)).

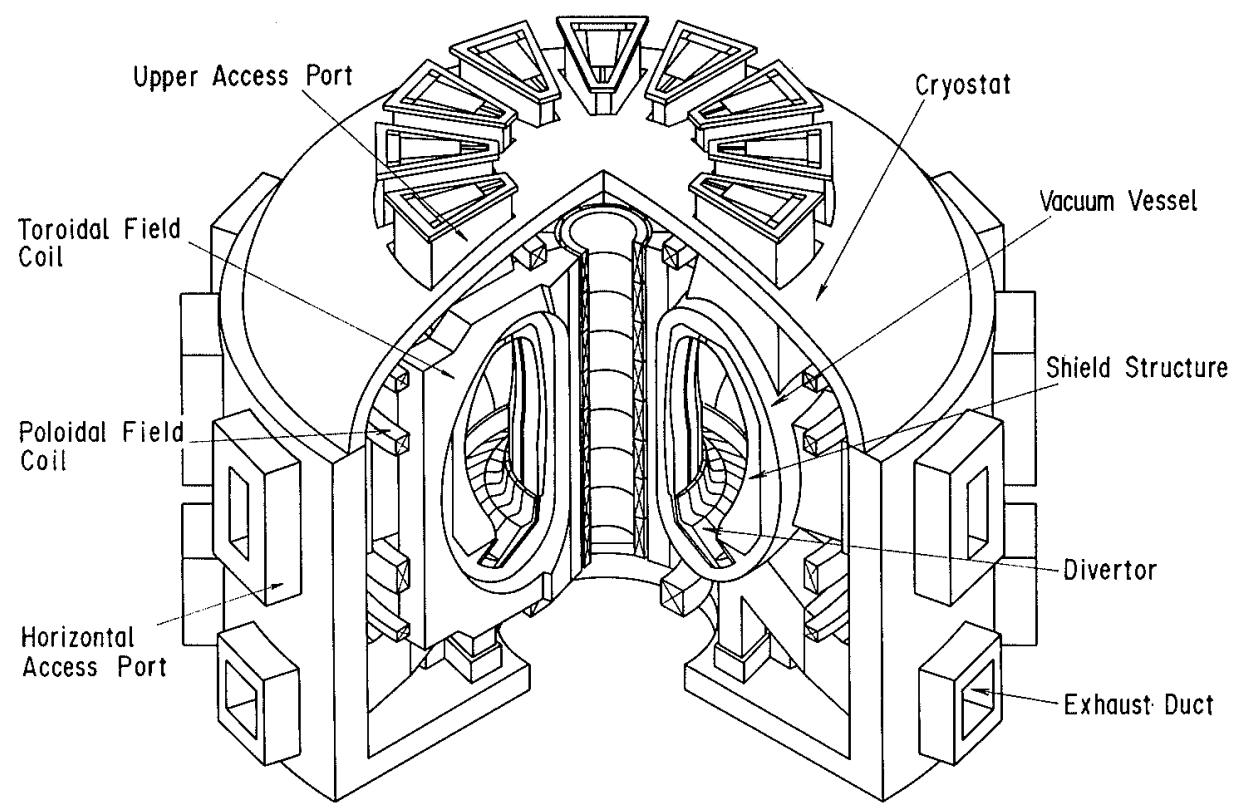

Fig. 1. A bird's-eye view of the FER.

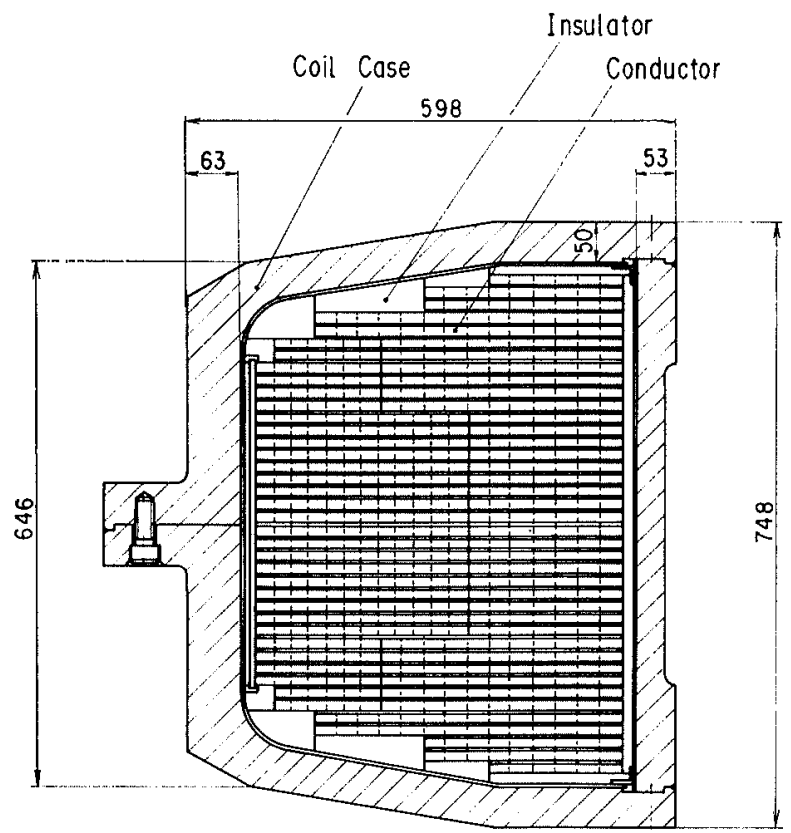

(a) The Japanese LCT coil case

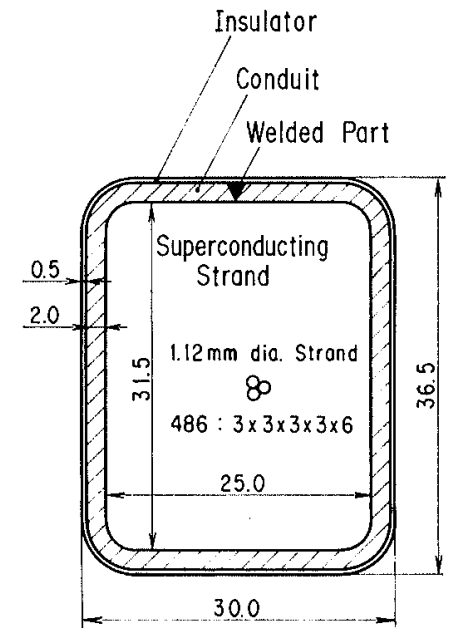

(b) The DPG conductor

Fig. 2. Examples from the application of structural materials to the $\mathrm{TF}$ coil case, and to the"cortuit of a conductor. 


\section{Requirements for New Gryogenic Structural Materials}

Structural materials for the superconducting coils of the FER must have higher strength and fracture toughness than nitrogen-bearing austenitic stainless steels such as 304LN and 316LN at liquid helium temperature. JAERI determined targets for the engineering properties of the structural materials before the specifications of the FER had been fixed. ${ }^{6,7)}$ The targets were as follows:

1) Yield strength: more than $1200 \mathrm{MPa}$ at $4 \mathrm{~K}$.

2) Fracture toughness: more than $200 \mathrm{MPa} \sqrt{\mathrm{m}}$ at $4 \mathrm{~K}$.

(Charpy absorbed energy: more than $100 \mathrm{~J}$ at $4 \mathrm{~K}$.)

3) Fatigue characteristics: similar to those of 316 austenitic stainless steel at $4 \mathrm{~K}$.

4) Magnetic permeability: not specified. (Non-magnetic material is preferred.)

5) Corrosion resistance: good rust resistance.

6) Good workability and weldability.

\subsection{Yield Strength}

The strength requirement for structural materials was determined from a stress analysis and the superconducting material properties. A preliminary stress analysis, performed in 1982, gave a stress of $400 \mathrm{MPa}$ on the conductor and $240 \mathrm{MPa}$ on the TF coil case. ${ }^{6)}$ As the conductor strain was limited due to the strain sensitivity of $\mathrm{Nb}_{3} \mathrm{Sn}$, the conductor had to be reinforced by strong structural materials. On the other hand, a detailed analysis indicated about three times the stress calculated by the preliminary analysis in case of the Japanese LCT coil. Therefore, we decided that a yield strength over I $200 \mathrm{MPa}$ was required if the design stress was two-thirds of the yield strength according to the ASME code. The maximum stress on the TF coil case is about $600 \mathrm{MPa}$ according to a recent analysis of the FER. ${ }^{8}$ This means that the determination in 1982 was reasonable despite the poor specification of the FER.
$\mathrm{Nb}_{3} \mathrm{Sn}$ superconducting material will be used to achieve the high field of $12 \mathrm{~T}$. In 1985, the high current $\mathrm{Nb}_{3} \mathrm{Sn}$ conductor technique was well established for high field generation in a large bore, since $12 \mathrm{~T}$ was generated by JAERI's Test Module Coil. ${ }^{9)}$ It was well known that there was a degradation of the critical current of $\mathrm{Nb}_{3} \mathrm{Sn}$ over a certain level of strain. These degradation characteristics in $\mathrm{Nb}_{3} \mathrm{Sn}$ were more pronounced at higher fields. The design limit of strain at $12 \mathrm{~T}$ had to be $0.5 \% .^{10}$ ) The elastic region of the conduit material had to exceed $0.5 \%$ strain to take advantage of the properties of $\mathrm{Nb}_{3} \mathrm{Sn}$. Consequently, a yield strength exceeding $1200 \mathrm{MPa}$ was also requested to extend the elastic behavior up to $0.5 \%$ strain.

\subsection{Fracture Toughness}

The fracture toughness target was determined from a crack propagation analysis of the coil case. The crack propagation was analyzed with the assumption that the plate thickness would be $100 \mathrm{~mm}$, a reasonable value in a large coil, and also that the initial crack radius would be $1 \mathrm{~mm}$. Fig. 3 shows the relation between crack size and number of cycles as a function of applied stress. The crack propagation length was calculated according to Paris's law. The value of the stress intensity factor, $K$, when the crack is through the thickness, is also shown in this figure. A fracture toughness of $200 \mathrm{MPa} \sqrt{\mathrm{m}}$ was required based on the design stress, the operation cycle, and the concept of "leak before break".

As it was not easy to measure fracture toughness, Charpy impact tests were performed instead of fracture toughness tests. The Charpy tests were performed to select candidate materials. A Charpy absorbed energy of $100 \mathrm{~J}$, the average value of $300-$ series austenitic stainless steels, was adopted as a target for development.

\subsection{Fatigue Characteristics}

The coil is exposed to large cyclic forces at cryo-
Fig. 3.

The relation between crack size and number of cycles as a function of applied stress.

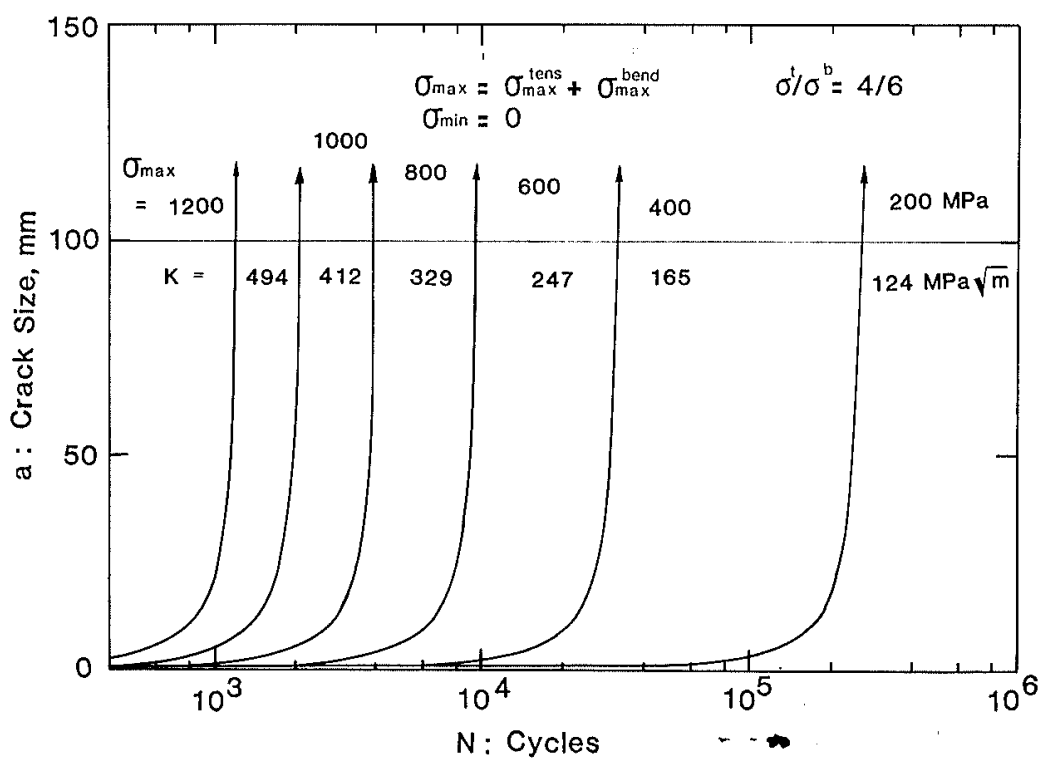


genic temperatures. It was difficult to determine the requirements for the fatigue characteristics due to the poor specification of the FER and lack of fatigue data at cryogenic temperatures. JAERI required the fatigue characteristics similar to 316 austenitic stainless steel because 316 austenitic stainless steel had the best fatigue characteristics at that time. ${ }^{11)}$

\subsection{Magnetic Permeability}

Ferromagnetic materials have never been used as structural materials for TF coils, because of the difficulty in calculating the magnetic field and force in consideration of the magnetic permeability. Using the computer code TRIM developed at Lawrence Livermore National Laboratory, we calculated the effect of magnetic permeability on the magnetic field when a ferromagnetic material is used for TF coil case. The calculated results for both a ferromagnetic material and a non-magnetic material are shown in Fig. 4. The maximum magnetic field on the coil case made of a ferromagnetic material is larger than that for a non-magnetic material. However, the difference is about $1 \mathrm{~T}$, corresponding to a saturated magnetization, and there is no effect on the winding and the plasma region. Thus, ferromagnetic materials can be used for the coil case of the TF coils and magnetic permeability was not specified.

\subsection{Rust Resistance}

The structural materials of the superconducting magnets may be wet with condensate during longterm operation and moisture will attack the surface of the structural materials of superconducting coils during the operation of FER. Rusting would cause a degradation of the vacuum and a heat leakage at $4 \mathrm{~K}$. Rust-resistant paint cannot be used because there is a difference in the thermal expansion between the structural materials and the paint. Therefore, rust-resistant structural materials were required.

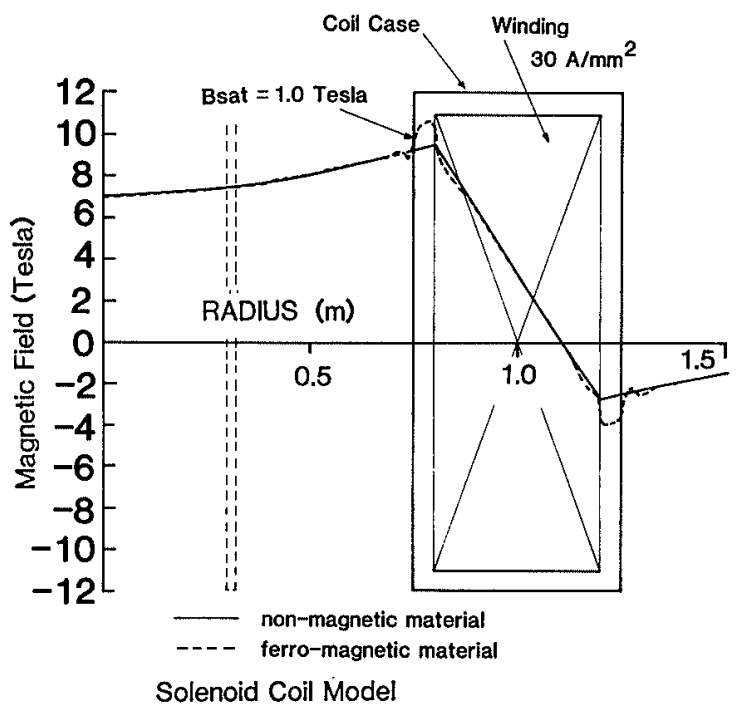

Fig. 4. The effect of the permeability of the coil case material on magnetic field distribution.

\section{Test Procedure and Specimen}

The data obtained by different laboratories could not be compared because there were no standards for cryogenic material testing. The method of testing at $4 \mathrm{~K}$ is very important in evaluating the material properties. Even though the standardization of cryogenic test methods has progressed by a US-Japan collaboration, there still remain several problems. ${ }^{12-14}$ To eliminate the difficulty of interlaboratory comparisons, it is necessary that only one laboratory conducts material tests at $4 \mathrm{~K}$ to select candidates from the materials produced by different steel companies. Therefore, all tests at $4 \mathrm{~K}$ were performed by JAERI in this development.

\subsection{Tension Test}

The tensile test specimen is cylindrical with a $7 \mathrm{~mm}$-diameter. It is cut from a rolled and forged plate so that the loading direction during the tests corresponds to the transverse direction of the plate. Tension tests at $4 \mathrm{~K}$ are carried out in a special tensile apparatus, "TURRET DISK"15), which makes it possible to test up to 10 specimens within a load limit of $10 \mathrm{t}$ in one cooldown cycle. Yield strength $(Y S)$ is measured at $0.2 \%$ plastic strain by an offset method applied to the load-strain curve. A strain gage is directly attached to the specimen. Ultimate tensile strength (UTS) is the maximum load divided by the original area. Elongation $(E L)$ is calculated by dividing the change in total length of a specimen by the original length of the reduced section. Reduction of area $(R A)$ is the change in cross section area divided by the original area. Tests are conducted using a screw-driven machine with crosshead displacement control and nominal strain rates of less than $3 \times 10^{-4} \mathrm{~s}^{-1}$ before $Y S$ measurement, and less than $1 \times$ $10^{-3} \mathrm{~s}^{-1}$ after $Y S$ measurement until fracture, where the nominal strain rate is calculated by dividing the crosshead speed by the initial length of the reduced section.

\subsection{Charpy Impact Test}

Charpy impact tests at $4 \mathrm{~K}$ are conducted by a technique different from the standard one. The specimen has a V-notch, a length of $55 \mathrm{~mm}$, and a square cross section of $10 \mathrm{~mm}$ as defined by the Japanese Industrial Standard (JIS), Z2022. The specimen is inserted in a small double-walled vacuuminsulated glass Dewar, which is capable of retaining liquid helium for several minutes. The Dewar containing the specimen and liquid helium is then placed on the anvil of the Charpy test machine and fractured. Little energy is required to break the glass Dewar, but a significant energy term arises, primarily because of the space between the specimen and the anvil. It is necessary to calibrate the test. ${ }^{3,7)}$ As the correction factor proves to be rather large, $33 \mathrm{~J}$, this method is suitable only for high toughness materials. However, it is useful to screen materials which have high absorbed energies over $100 \mathrm{~J}$ in our development. 


\subsection{Fracture Toughness $\left(J_{\mathrm{Ic}}\right)$ Test}

Large specimens and large capacity machines are necessary to measure the valid plane-strain fracture toughness, $K_{\text {Ic }}$, of high fracture toughness materials, according to ASTM E399. Assuming $K_{\text {Ic }}$ corresponds to elastic-plastic fracture toughness $J_{\text {Ic }}$, the $K_{\text {Ic }}$ value can be estimated from $J_{\text {Ic }}$. Therefore, the $J_{\text {Ie }}$ test, in which a small specimen can be used, is usually conducted instead of the $K_{\text {Ic }}$ test.

Desirable features for measuring the mechanical properties of structural materials at $4 \mathrm{~K}$ are:

1) Efficient use of liquid helium; and

2) Simple test procedure.

The single-specimen method is the most suitable one at liquid helium temperature owing to its small liquid helium consumption. There are several single-specimen methods, such as the unloading compliance method, the electrical potential method, the ultrasonic method, and the acoustic emission method. JAERI has adopted a computerized $J_{\text {Ic }}$ test method using the unloading compliance technique because this method satisfies the above requirements. $J_{\text {Ic }}$ tests are conducted using clip gage displacement control with a servohydraulic machine.

JAERI verified the reliability of the unloading compliance method by comparing this method and the standard method according to ASTM E813-81 at $4 \mathrm{~K}$. The test material was $25 \mathrm{Cr}-13 \mathrm{Ni}$ austenitic stainless steel, supplied from $70 \mathrm{t}$ industrial heats. This steel, which has a $4 \mathrm{~K}$ yield strength of 1450 $\mathrm{MPa}$, is one of the newly developed steels. The results of the verification test are shown in Fig. 5. ${ }^{16)}$ The $R$-curve obtained by the unloading compliance method corresponds to that measured by the 1981 standard multiple-specimens method. The $K_{\text {Ic }}$ values measured by both methods are 190 and $182 \mathrm{MPa} \sqrt{\mathrm{m}}$, respectively. In recent years, round robin tests to establish the cryogenic test standards were performed in a US-Japan collaboration. ${ }^{12,13)}$ The reliability of JAERI's system and the unloading compliance method were demonstrated through these tests.

Specimens used in these $J_{\mathrm{rc}_{c}}$ tests are proportional CT specimens, defined by ASTM E813-81, having a $25 \mathrm{~mm}$-thickness and $26.5 \mathrm{~mm}$ notch length. The notch orientation is TL, and displacement is measured at the loadline. Specimens are precracked by each steel industry at room temperature. The maxi- mum stress intensity factor and ratio of initial crack length to width are less than $33 \mathrm{MPa} \sqrt{\mathrm{m}}$ and about 0.6 , respectively.

\section{Development of the New Gryogenic Struc- tural Materials}

\subsection{Development Procedure}

Under the collaboration contracts, the industries manufacture potential cryogenic steels. Then they carry out tension and Charpy impact tests on the steels at room temperature and at liquid nitrogen temperature. Thereafter, JAERI conducts similar mechanical tests at liquid helium temperature $(4 \mathrm{~K})$. The data obtained at JAERI are presented to the steel manufacturers for the purpose of improvement. This is the first of 3 steps to develop the candidate structural materials for the FER as shown in Fig. 6.17) As minimum values for the yield strength and the Charpy absorbed energy at $4 \mathrm{~K}$ in the first step of screening, we specify $1200 \mathrm{MPa}$ and $100 \mathrm{~J}$, respectively. In the second step, fracture toughness tests by means of the compliance method are performed on the materials which passed the first step. Finally, JAERI selects materials for the FER after the third step in which fatigue tests are carried out.

\subsection{Materials}

Materials evaluated at JAERI are classified into ferritic steels (FS), high manganese austenitic steels

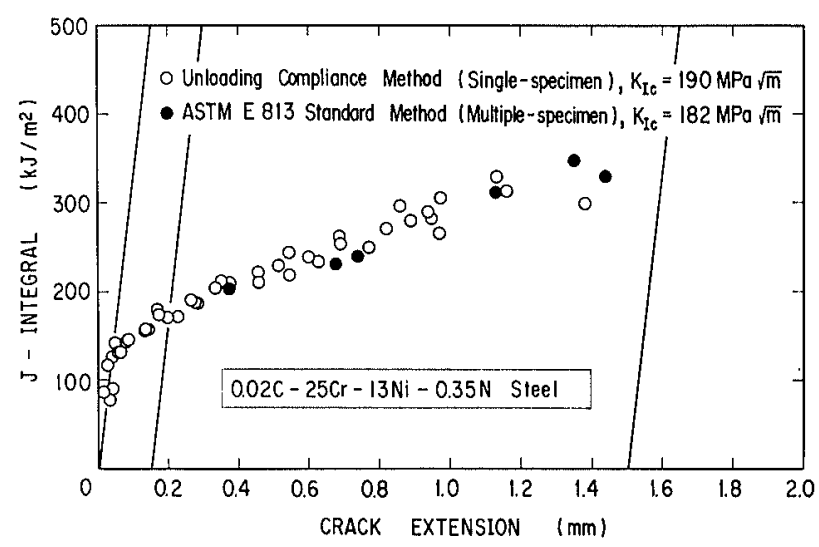

Fig. 5. Comparison with the ASTM standard method and the unloading compliance method in the $J_{\mathrm{IC}}$ tests at $4 \mathrm{~K}$.
Fig. 6.

Development process of the new cryogenic steels.

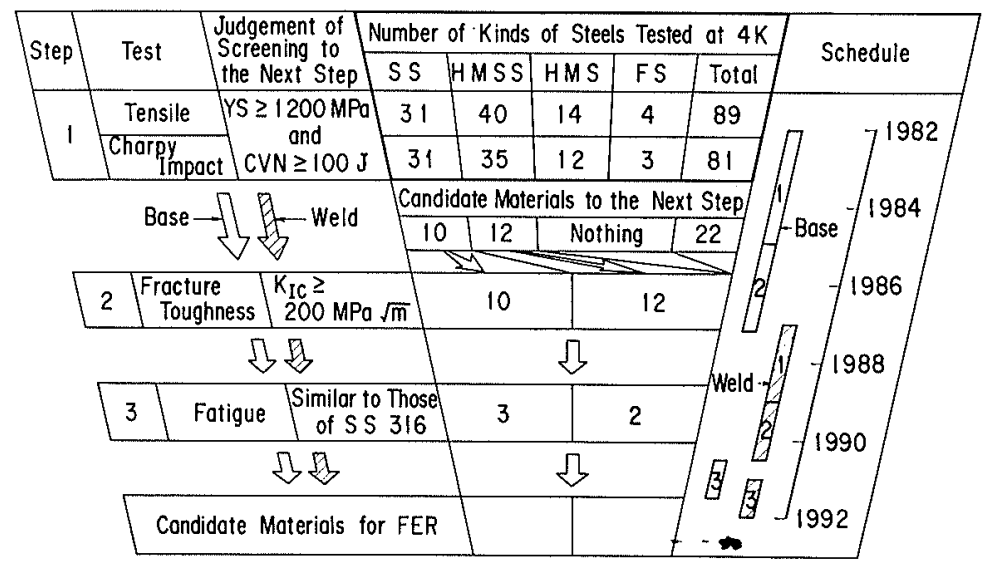


(HMS), austenitic stainless steels (SS), and high manganese austenitic stainless steels (HMSS). The number of different kinds of steels tested up to now at $4 \mathrm{~K}$ is also shown in Fig. 6. Tested steels are all newly developed cryogenic materials except for a few austenitic stainless steels and ferritic steels such as $9 \% \mathrm{Ni}$ and maraging steel.

\subsection{Results of Screening Tests}

Fig. 7 shows the relation between the Charpy absorbed energy and the yield strength. ${ }^{17}$ ) Our target shown by the hatched area is located over the line which is extrapolated from 304LN and 316LN austenitic stainless steels. All test results are plotted in this figure. The materials that satisfy the target are austenitic stainless steels and high manganese austenitic stainless steels, except for one ferritic steel and 3 high manganese austenitic steels. The structural materials of the Japanese LCT coil, 304LN manufactured by the electron slag remelting (ESR) process, shows high energy compared with conventional $304 \mathrm{LN}$ and $316 \mathrm{LN}$ steels. This suggests that the

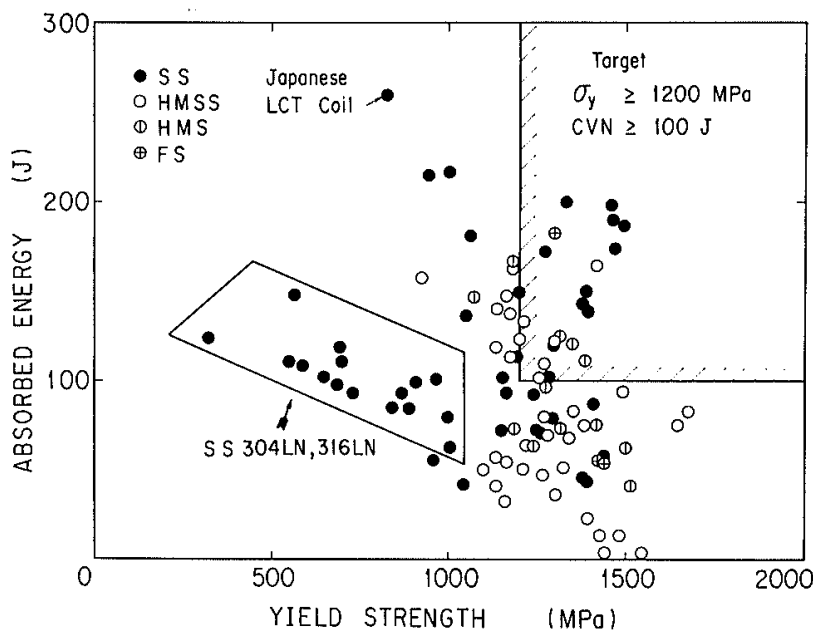

Fig. 7. The relation between Charpy absorbed energy and yield strength at $4 \mathrm{~K}$. purity of the material affects its toughness. JAERI decided that the austenitic stainless steel development should be continued, and stopped the development of ferritic and high manganese steels. The reason was the poor rust resistance of the latter.

Fig. 8 shows the relation between fracture toughness and yield strength. The target, called "JAERI Box ", is also located above the trend line for 304-type stainless steels measured by the National Institute of Standards and Technology (formerly National Bureau of Standards). ${ }^{18)}$ The results for materials that passed the goals of tension and Charpy tests are plotted in this figure. Half of the tested materials satisfy the target. High $\mathrm{Cr}-\mathrm{Ni}$ austenitic stainless steels have a better balance of fracture toughness and yield strength in comparison with high $\mathrm{Mn}$ austenitic stainless steels.

The fracture toughnesses of the tested materials were greatly improved by changes in their chemical composition, production process, and quality control. The fracture toughnesses of the tested materials range from 180 to $240 \mathrm{MPa} \sqrt{\mathrm{m}}$. The yield strength divides the tested materials into two groups, as shown in Fig. 9. ${ }^{16)}$ The yield strength difference are due to the effect of nitrogen content on cryogenic strength. The nitrogen contents of the first and second group of steels are about 0.2 and $0.35 \%$, respectively. The yield strength dependence on nitrogen content is wellknown. ${ }^{18,19)}$ One of the authors reported the effect of nitrogen content on the cryogenic strength of 300series austenitic stainless steels. ${ }^{3)}$ The results for developmental steels indicate a similar effect. The fracture toughness, however, is independent of nitrogen content, as shown in Fig. 9. It may depend on other factors, for example, material impurities.

\section{Japanese Cryogenic Steels (JCS)}

\subsection{Mechanical Properties of the Base Metals}

From the screening tests, 5 materials were selected and then produced on an industrial scale. These

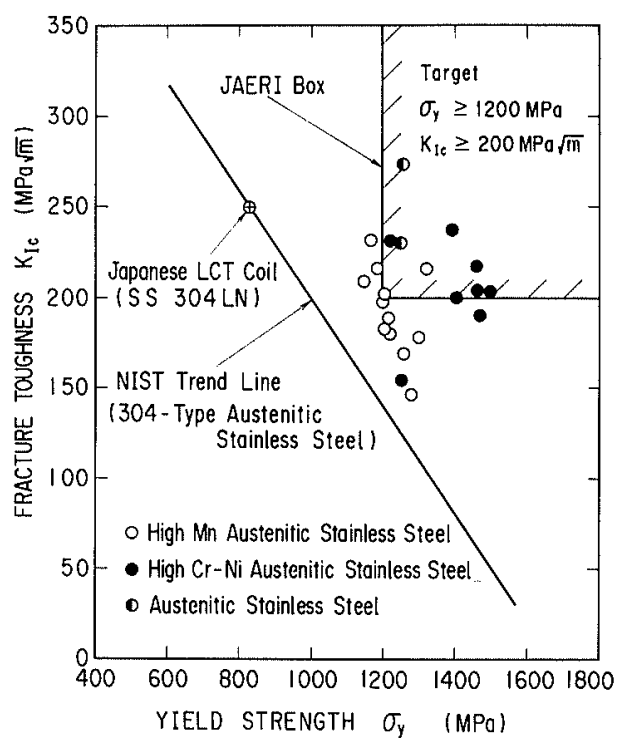

Fig. 8. The relation between fracture toughness and yield strength at $4 \mathrm{~K}$.

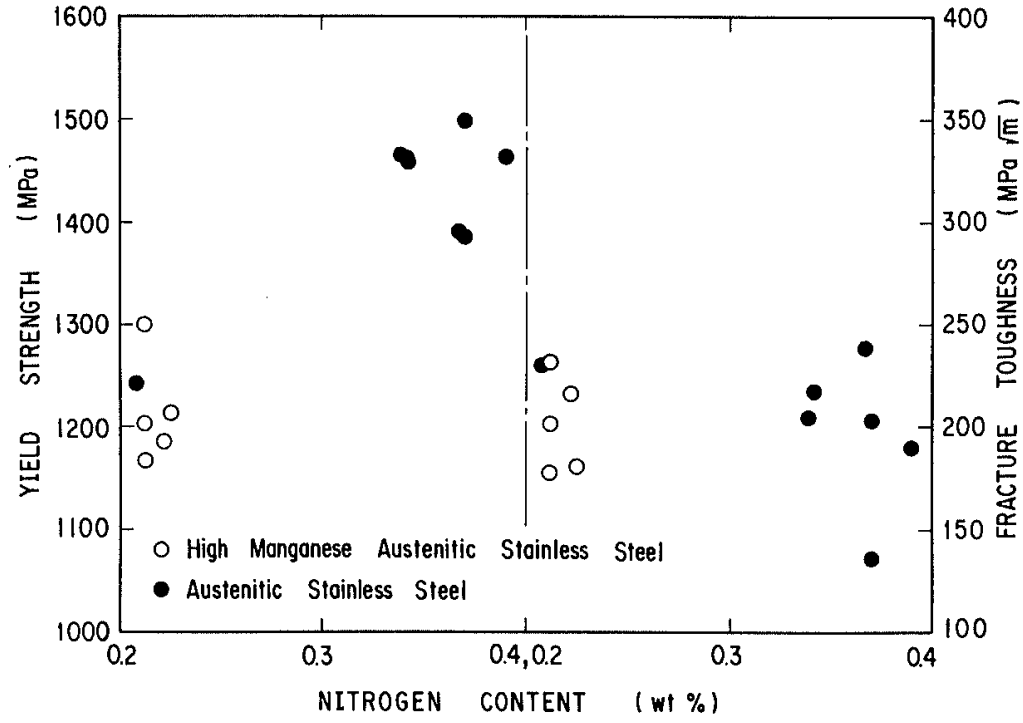

Fig. 9. The effect of nitrogen content on yield strength and fracture toughness of the new cryogenic steels. 
structural alloys were named "Japanese Cryogenic Steels" (JCS). Each name and the corresponding chemical composition is shown in Table 1. All steels are austenitic stainless steels. Two are high $\mathrm{Cr}-\mathrm{Ni}$ (CSUS-JN 120,21), JKA 122), two are high Mn (GSUS$\left.\mathrm{JN} 2^{21,23,24)}, \mathrm{JK}^{251}\right)$, and one has medium chemical composition (CSUS-JJ 126)).

The tensile properties of the JGS are shown in Table 2. The JGS have both high strength and high ductility at $4 \mathrm{~K}$. Fig. 10 shows a typical stress-strain curve for a new cryogenic stainless steel. ${ }^{27)}$ The stress-strain curve shows a unique and strange behavior, called serration, in the plastic region at $4 \mathrm{~K}$ as shown in Fig. 10. The JCS have higher yield strengths than 300 -series austenitic stainless steels. But it has lower ductility than that of 300 -series austenitic stainless steels. When serrations occur, the load drops for the new cryogenic structural materials are larger than those for 304LN austenitic stainless steel as shown in Fig. 10.

The test rate is an important factor influencing mechanical properties at $4 \mathrm{~K}$. Fig. 11 shows the yield and ultimate tensile strengths of GSUS-JK2 with varying test rate. Yield strength is not influenced by the test rate, but ultimate tensile strength

Table 2. Mechanical properties of the JCS base metals.

\begin{tabular}{lccccccc}
\hline \multicolumn{1}{c}{ JCS } & $\begin{array}{c}Y S \\
(\mathrm{MPa})\end{array}$ & $\begin{array}{c}T S \\
(\mathrm{MPa})\end{array}$ & $\begin{array}{c}E L \\
(\%)\end{array}$ & $\begin{array}{c}R A \\
(\%)\end{array}$ & $\begin{array}{c}C V N \\
(\mathrm{~J})\end{array}$ & $\begin{array}{c}J_{\mathrm{Ic}} \\
(\mathrm{kJ} / \\
\left.\mathrm{m}^{2}\right)\end{array}$ & $\begin{array}{c}K_{\mathrm{Ie}} \\
(\mathrm{MPa} \sqrt{\mathrm{m}})\end{array}$ \\
\hline CSUS-JN1 & 1403 & 1782 & 40 & 52 & 183 & 196 & 201 \\
CSUS-JKA1 & 1295 & 1534 & 34 & 49 & 250 & 460 & 302 \\
CSUS-JN2 & 1215 & 1603 & 36 & 46 & 125 & 182 & 189 \\
CSUS-JK2 & 1203 & 1623 & 39 & 52 & 124 & 188 & 202 \\
CSUS-JJ1 & 1110 & 1574 & 43 & 51 & 185 & 372 & 267 \\
\hline
\end{tabular}

Table 1. Chemical compositions of the JCS.

\begin{tabular}{llcccccccccc}
\hline JCS & $\mathrm{C}$ & $\mathrm{Si}$ & $\mathrm{Mn}$ & $\mathrm{P}$ & $\mathrm{S}$ & $\mathrm{Ni}$ & $\mathrm{Cr}$ & $\mathrm{Mo}$ & $\mathrm{N}$ & Others \\
\hline CSUS-JN1 & 0.026 & 0.99 & 4.2 & 0.026 & 0.002 & 14.74 & 24.2 & - & 0.34 & \\
CSUS-JKA1 & 0.023 & 0.42 & 0.49 & 0.006 & 0.001 & 14.0 & 25.0 & 0.68 & 0.268 & $\mathrm{~V}: 0.30$ \\
GSUS-JN2 & 0.050 & 0.34 & 22.4 & 0.010 & 0.002 & 3.22 & 13.4 & 0.70 & 0.24 & $\mathrm{Cu}: 0.70$ \\
CSUS-JK2 & 0.05 & 0.36 & 21.79 & 0.013 & 0.005 & 4.94 & 12.82 & - & 0.212 & & \\
CSUS-JJ1 & 0.046 & 0.44 & 9.74 & 0.020 & 0.002 & 11.92 & 12.21 & 4.89 & 0.203 & \\
\hline
\end{tabular}

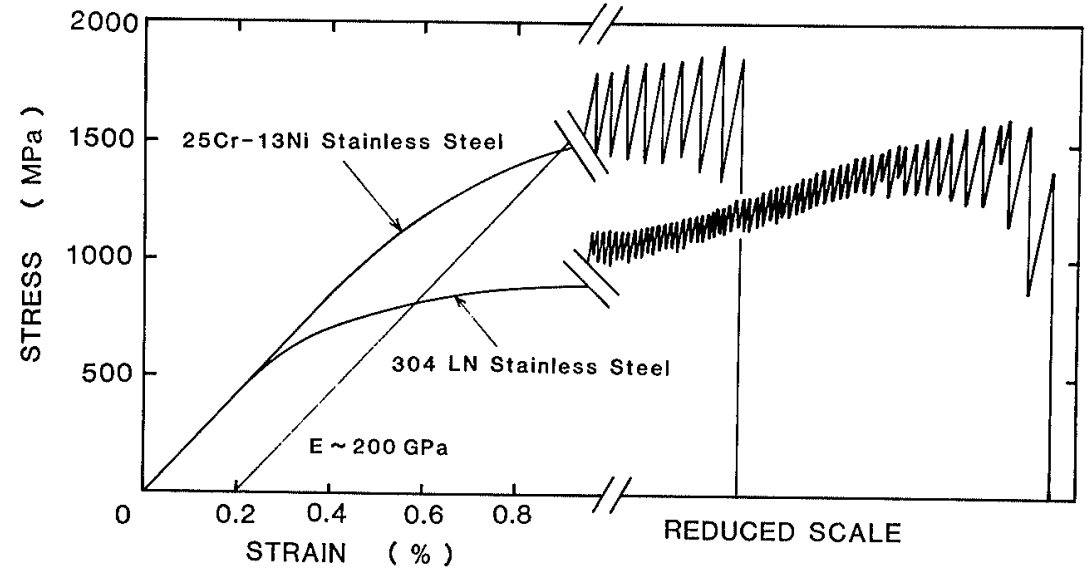

Fig. 10.

Typical stress-strain curves of the new cryogenic steel and 304LN ordinary austenitic stainless steel.
Fig. 11.

The effect of test rate on yield and ultimate tensile strength of CSUS-JK2.

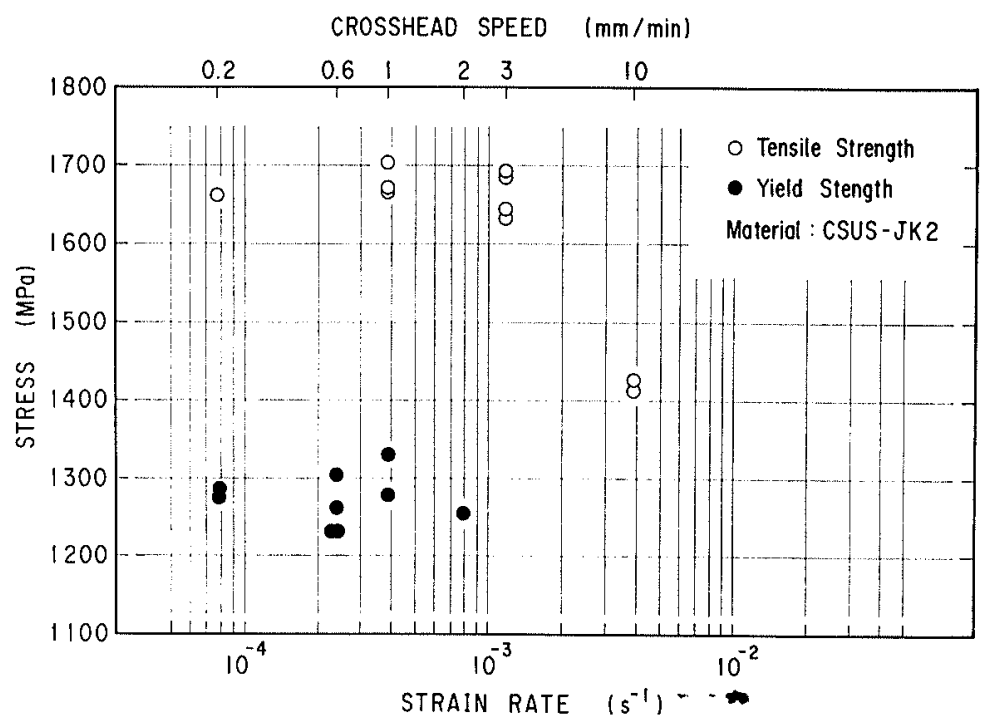


is decreased at test rates higher than $10^{-3} \mathrm{~s}^{-1}$. Serration phenomena also change with the test rate. Serrations do not occur at high test rates, due to extreme adiabatic heating of the material. With regard to tension test, a consensus method was established under a US-Japan collaboration, and it will be standardized in both countries as the JIS (Japan) and ASTM (US) standards. ${ }^{13)}$ The test rate recommended by the standard is less than $10^{-3} \mathrm{~s}^{-1}$. The maximum rates in our tension tests are below that limit.

Fracture toughness data for the JCS are also shown in Table 2. During fracture toughness tests, serrations occur in the plastic region as observed during the tension tests. Small unstable crack growth, like pop-in cracks, can occur during serrations. However, the JCS materials do not fracture in an unstable fashion. Consequently, the JCS has high fracture toughness.

\subsection{Mechanical Properties of Weldments}

The requirements for the mechanical properties of weldments are the same as those for the base metals at cryogenic temperatures. Usually, however, weldment properties decrease compared to the base metals. Therefore, we adopted weldments which had the best properties, even if their mechanical properties did not satisfy the target. Tungsten inert gas (TIG) welding and electron beam (EB) welding were applied to the JCS, and these weldments have been evaluated now. ${ }^{28,29)}$

The mechanical properties of the weldments are shown in Table 3. The strength of TIG welded joints is lower than that of the base metals. The fracture toughnesses of TIG joints are also lower than those of the base metals. On the other hand, the EBW properties compare favorably with those of the base metals. In fact, the fracture toughnesses of EBW joints of CSUS-JN1, JN2, JK2 are higher than those of the base metals.

\section{Application of the JGS}

\subsection{Verification Test to Apply the JCS}

\subsubsection{Thick Plate}

(1) Effects of Specimen Size

Plates more than $100 \mathrm{~mm}$ thick will be used in the superconducting coils of the FER. The mechanical properties are evaluated using small specimens because there is a load limitation on machine due to the liquid helium environment. The size of laboratory specimens is small compared with the actual plate thicknesses. It is required that the effect of specimen size is clarified in order to design and construct reliable coils. Therefore, JAERI installed a large servohydraulic tensile machine of 100-t capacity in 1986 to enable the testing of large specimens. The effect of specimen size on tensile and fracture toughness properties of the JCS were investigated. ${ }^{30}$ ) Fig. 12 shows the cryogenic apparatus of the 100-t testing machine. Cryogenic tests were performed in the cryostat which is $3 \mathrm{~m}$ deep. Specimens for the ten-
Table 3. Mechanical properties of the JCS weldments.

\begin{tabular}{clcccc}
\hline JCS & & $\begin{array}{c}Y S \\
(\mathrm{MPa})\end{array}$ & $\begin{array}{c}\text { TS } \\
(\mathrm{MPa})\end{array}$ & $\begin{array}{c}J_{\mathrm{Ic}} \\
\left(\mathrm{kJ} / \mathrm{m}^{2}\right)\end{array}$ & $\begin{array}{c}K_{\text {Ic }} \\
(\mathrm{MPa} / \mathrm{m})\end{array}$ \\
\hline CSUS-JN1 & TIG & 1196 & 1553 & 139 & 167 \\
& EBW & 1396 & 1761 & 290 & 242 \\
CSUS-JKA1 & TIG & & & & \\
& EBW & 1293 & 1602 & & \\
CSUS-JN2 & TIG & 1138 & 1449 & 128 & 157 \\
& EBW & 1287 & 1646 & 230 & 216 \\
CSUS-JK2 & TIG & 1316 & 1535 & 125 & 155 \\
& EBW & 1173 & 1604 & 269 & 241 \\
CSUS-JJ1 & TIG & 1207 & 1499 & 197 & 195 \\
& EBW & 1229 & 1604 & 307 & 242 \\
\hline
\end{tabular}

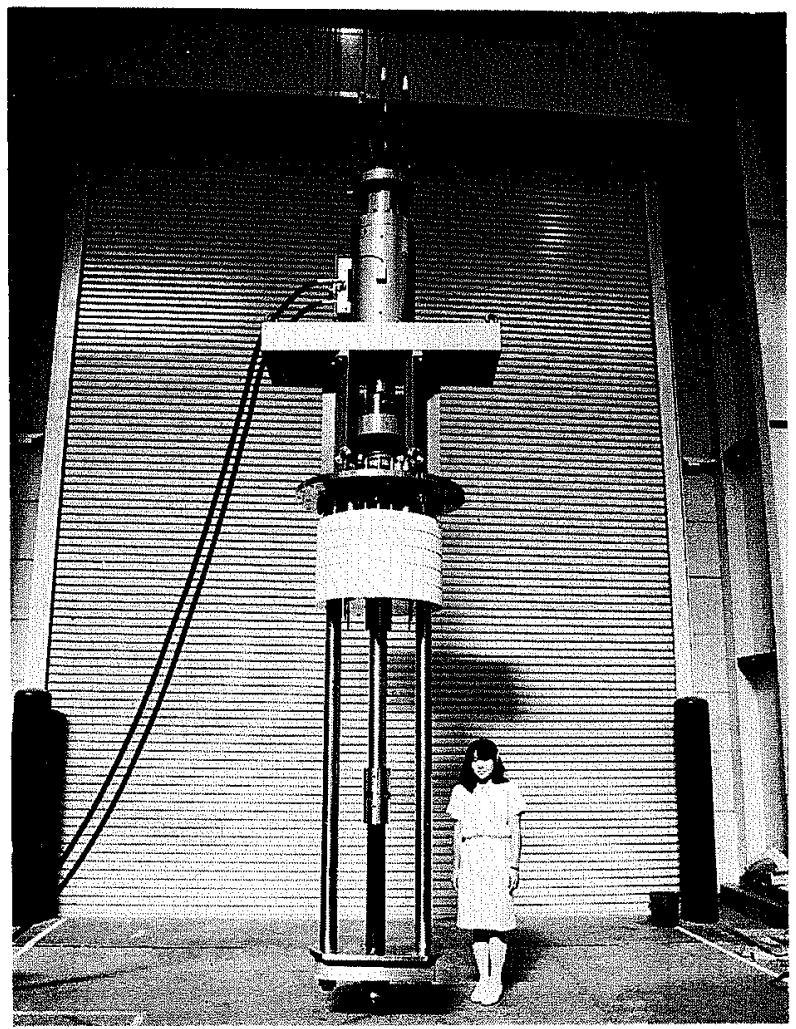

Fig. 12. The cryogenic apparatus of 100 -t testing machine

sion and fracture toughness tests are indicated in Figs. 13 and 14, respectively. Tensile specimens of 25-mm diameter and CT specimens of 75- or 100-mm thickness are used in the 100-t testing machine.

Fig. 15 shows a load-time chart for a CSUS-JJ1 tension test with a large specimen. The observed tensile behavior is similar to that of the 7-mm specimen. Fig. 16 compares the mechanical properties of the 7-and $25-\mathrm{mm}$ specimens. Ultimate tensile strength and reduction of area slightly decrease with increased specimen diameter. However, the decreases are equivalent to measurement uncertainties for the material properties. Since the effect of the specimen diameter on the mechanical properties is small, we conclude that $7-\mathrm{mm}$ specimens are adequate to evaluate the tensile properties of thick plates. Furthermore, many data from the $7-\mathrm{mm}$ specimen are more significant than fewer data from the $25-\mathrm{mm}$ specimen to design and construct the superconducting magnets. 
The reason is that it is possible to test about 30 small specimens in the amount of time that it takes to test only one large specimen.

Very interesting with regard to fracture toughness is whether or not the JCS fracture unstably at the $K_{\text {Ic }}$ value. The effect of specimen size in fracture toughness is more important than in tensile properties, from the view point of fracture mechanics. Fig. 17 shows $J_{\text {Ic }}$ vs. specimen thickness for GSUS-JN1 and JJ1. There is little or no size effect in thick specimens and brittle fracture does not occur even if the plane strain condition is satisfied. However, the fracture toughness of $12.5 \mathrm{~mm}$ thick CSUS-JJ1 specimens is higher than those of other thicknesses. This suggests that larger specimens than those required by fracture mechanics may be needed for $J_{\text {Ic }}$ tests.

(2) Effects of Test Control in Fracture Toughness Tests

The loads applied to superconducting coils will

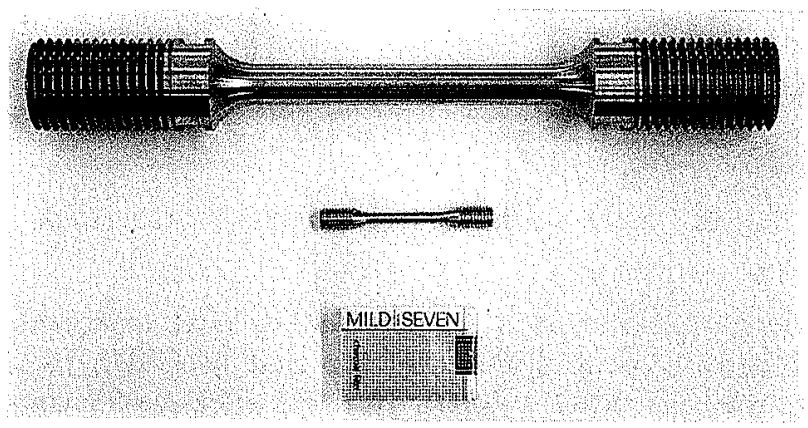

Fig. 13. 7-mm diameter and 25-mm diameter tensile specimens.

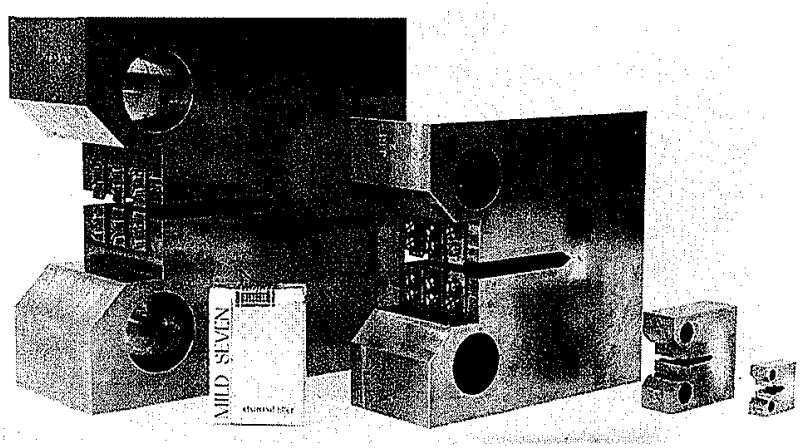

Fig. 14. Fracture toughness specimens of 4 kinds of thickness $(12.5,25,75,100-\mathrm{mm}$ thickness CT specimens). be not displacement-controlled but load-controlled. Usually, fracture toughness tests are conducted using displacement control. To design reliable superconducting magnets it is significant to observe the material behavior under load control. Fig. 18 shows loaddisplacement curves of 3 different controls for $25 \mathrm{~mm}$ thick CT specimens. Load-drops during serrations are sharp when displacement control is used. On the other hand, no load-drops and rapid increase of displacement occurs when tests are conducted using load control. Fig. 19 shows $J-\Delta a$ curves for 3 controls. All data points are on the same curve up to the

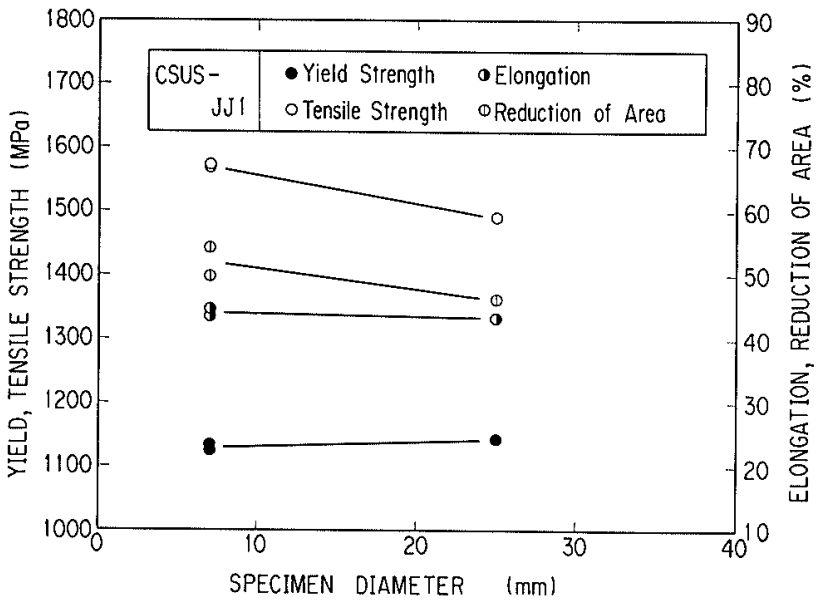

Fig. 16. The effect of specimen diameter on tensile properties of CSUS-JJ1.

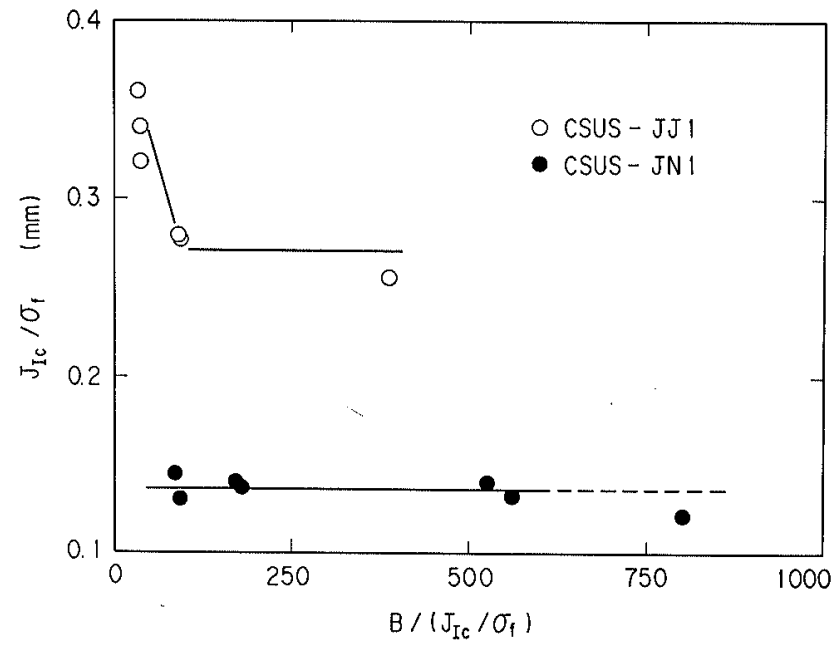

Fig. 17. The effect of specimen thickness on fracture toughness of CSUS-JJ1 and CSUS-JN1.
Fig. 15.

Load-time chart of CSUS-JJ1 tested with a large specimen of $25 \mathrm{~mm}$ diameter.

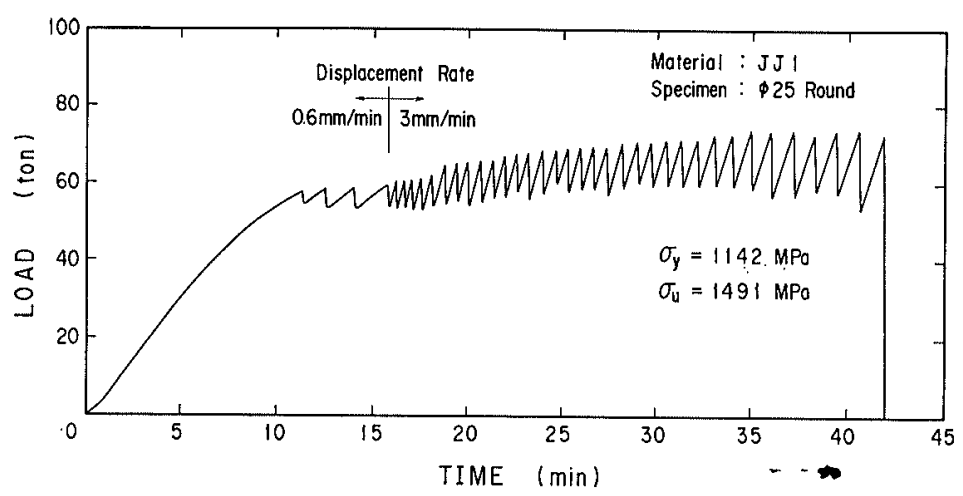




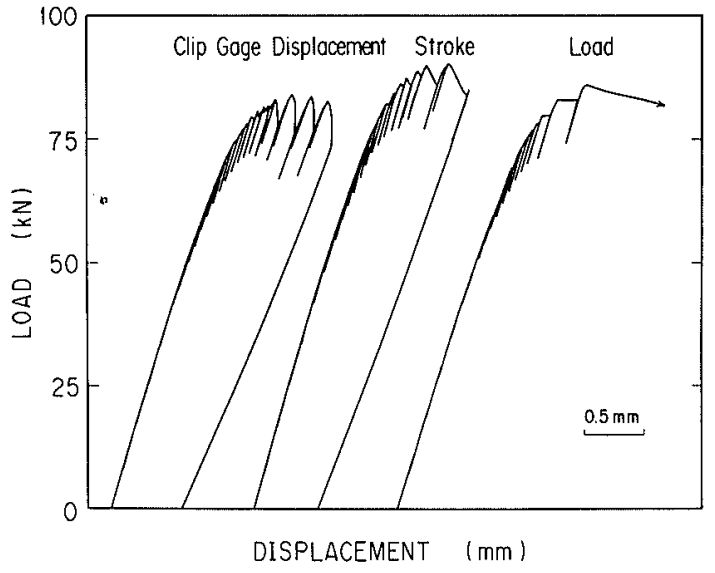

Fig. 18. Load-displacement curves of CSUS-JN1 in $J_{\text {Ie }}$ tests conducted with 3 different controls.

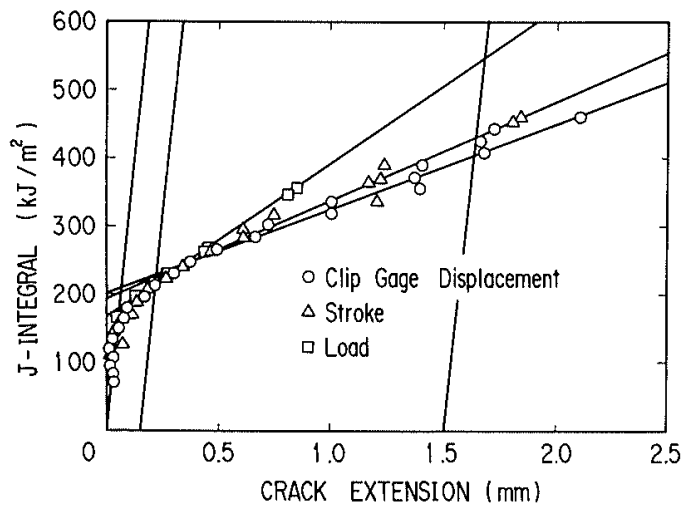

Fig. 19. R-curves of CSUS-JN1 in $J_{\text {Ic }}$ tests conducted with 3 different controls.

$0.15-\mathrm{mm}$ offset line. But the slope of the regression line using load control is larger than that using other controls, due to different behavior observed in the load-displacement curve when serration occurs. Consequently, the test using load control indicates lower $J_{\text {Ie }}$ as compared with stroke or displacement control tests. The JCS, however, did not exhibit brittle fracture even when fracture tests were conducted using load control.

\subsubsection{Thin Plate}

Thin plates are used for the conduit material of a conductor. The base materials and weldments suffer from cold working when the conductor is formed. In addition, the conduit material for $\mathrm{Nb}_{3} \mathrm{Sn}$ conductors suffers from the reaction heat treatment (for example, $700^{\circ} \mathrm{C} \times 200 \mathrm{~h}$ ), which degrades the ductility of the material due to sensitization. Some verification tests to clarify these problems were conducted before application of the JCS to conduits. ${ }^{31}$ ) Tested materials were CSUS-JN1, JN2, JK2 and JKAl. In addition, specially developed CSUS-JK1,32) whose ductility does not decrease after the $\mathrm{Nb}_{3} \mathrm{Sn}$ reaction heat treatment, was tested. The yield and tensile strengths of a thin plate in the solution treated state slightly increased in comparison with that of a thick plate. Both the yield and tensile strengths slightly decreased due to heat treatment. The effect of heat treatment on elongation is a serious problem in some JCS. The

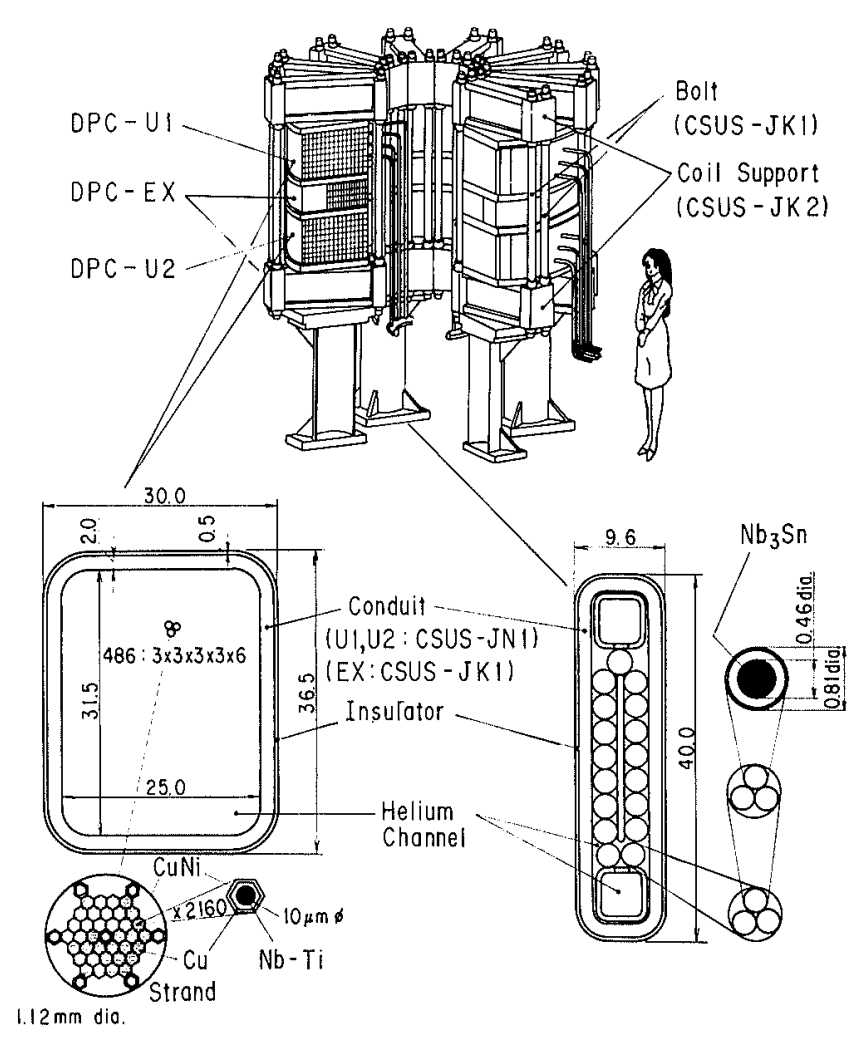

Fig. 20. Applications of the JCS to the Demo Poloidal Coils.

elongation of materials subjected to heat treatment drastically degrades, except for that of CSUS-JK1. It was verified that CSUS-JK1 was effective for conduits which suffer from $\mathrm{Nb}_{3} \mathrm{Sn}$ activation heat treatment, and also that other JGS could be used for the conduits of $\mathrm{Nb}-\mathrm{Ti}$ conductors.

\subsection{Application to the Real Coil}

JAERI used the JCS as structural materials for the Demo Poloidal Coils (DPG), ${ }^{33,34)}$ The DPC project aims to develop the technology for the ohmic heating coils of the FER. These coils suffer from complicated cyclic forces due to pulsed operation for plasma ignition. The DPG is composed of three coils; a pair of $\mathrm{Nb}-\mathrm{Ti}$ forced-flow coils (DPG-U1, U2) and a $\mathrm{Nb}_{3} \mathrm{Sn}$ forced-flow coil (DPG-EX) installed between DPCU1 and DPG-U2. Fig. 20 shows a schematic of the DPG. The JCS used in the DPG were thick plates for the coil supports and bolts, and thin plates for the conduit materials and the cryogenic buffer tank. CSUS-JK2 and JK1 were used as coil supports and bolts, respectively. CSUS-JNI and JKI were used for the conduit material of the DPC-U1, U2 and DPG-EX, respectively. In addition, CSUS-JKAl was used for the cryogenic buffer tank.

\section{Summary}

JAERI, in collaboration with 4 steel companies, has successfully developed new cryogenic steels, JCS, for the superconducting magnets of the FER. The new steels have high strength-toughness combinations $\left(\sigma_{y}>1200 \mathrm{MPa}, K_{\mathrm{Ic}}>200 \mathrm{MPa} \sqrt{\mathrm{m}}\right)$ that are beyond the capability of conventional-astenitic stainless steels 


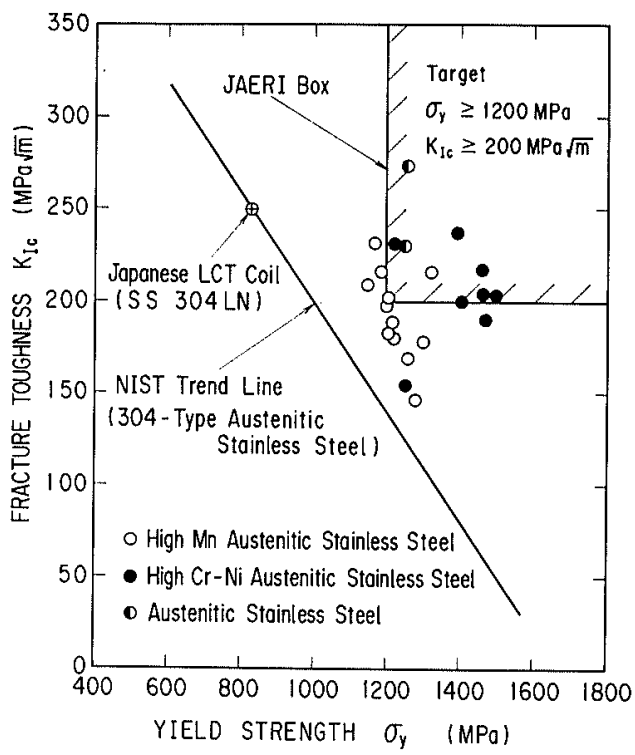

Fig. 21. The relation between fracture toughness and yield strength of the JGS at $4 \mathrm{~K}$.

for cryogenic use, as shown in Fig. 21. These steels have been already used as the structural materials of real superconducting coils, JAERI's Demo Poloidal Goils.

The successful development of JCS was achieved due to the good combination of JAERI's activities and facilities for $4 \mathrm{~K}$ material testing, and the excellent capabilities for steel development in Japanese companies. There are no steels similar to JCS in terms of strength and toughness in the world. It was discussed that JCS would be used as the structural materials for the superconducting magnets of the International Thermonuclear Experimental Reactor (ITER). JCS are also available for use in other fields such as high energy physics, MHD power generators, superconducting power generators, and magnetically levitated trains.

\section{Acknowledgments}

The authors would like to thank Drs. M. Yoshikawa and M. Tanaka, Japan Atomic Energy Research Institute, for their continuous encouragement of this work. This development was carried out in collaboration with Japan Steel Works Ltd., Kawasaki Steel Corporation, Kobe Steel, Ltd. and Nippon Steel Corporation. Without such collaboration, the development of the JCS would not have been possible. The authors wish to express appreciation to all the participants in each industry for their contributions.

\section{REFERENCES}

1) S. Shimamoto, T. Ando, T. Hiyama, H. Tsuji, Y. Takahashi, E. Tada, M. Nishi, K. Yoshida, K. Okuno, K. Koizumi, T. Kato, H. Nakajima, O. Takahashi, M. Shimada, Y. Sanada, F. Iida and K. Yasukochi: IEEE Trans. Magn., MAG-19 (1983), 851.

2) S. Shimamoto, T. Ando, T. Hiyama, H. Tsuji, Y. Takahashi, M. Nishi, E. Tada, K. Yoshida, K. Okuno, K. Koizumi, H. Nakajima, T. Kato and K. Yasukochi: Cryogenics, 25
(1985), 227

3) Y. Takahashi, K. Yoshida, M. Shimada, E. Tada, R. Miura and S. Shimamoto: Advances in Cryogenic Engineering Materials, Vol. 28, Plenum Press, New York, (1982), 73.

4) R. Miura, K. Ohnishi, H. Nakajima and S. Shimamoto: Tetsu-to-Hagané, 73, (1987), 715.

5) E. Tada, K. Shibanuma, M. Sugihara, K. Yoshida, H. Tsuji, S. Shimomura, S. Matsuda, T. Abe, N. Fujisawa, M. Hasegawa, T. Honda, T. Horie, H. Hosobuchi, H. Iida, S. Ishida, S. Kashihara, H. Kimura, K. Koizumi, T. Kuroda, Y. Kusama, K. Maki, T. Matoba, F. Matsuoka, T. Mizoguchi, M. Mori, H. Naruse, T. Nishio, Y. Ohara, Y. Ohkawa, K. Okuno, K. Sato, S. Seki, Y. Seki, Y. Shinya, H. Takatsu, S. Tanaka, T. Takizuka, T. Tsunematsu, S. Yamamoto and $\mathrm{H}$. Yoshida: Proc. 13th Symp. on Fusion Eng., (1989), 239.

6) K. Yoshida, H. Nakajima, K. Koizumi, M. Shimada, Y. Sanada, Y. Takahashi, E. Tada, H. Tsuji and S. Shimamoto: Austenitic Steels at Low Temperature, Plenum Press, New York, (1983), 29.

7) H. Nakajima and S. Shimamoto: J.At. Energy Soc. Jpn., 27 (1985), 9.

8) K. Koizumi, K. Yoshida, M. Hasegawa, K. Okuno, E. Tada, K. Konno, H. Tsuji, S. Matsuda and S. Shimamoto: Proc. 13th Symp. on Fusion Eng., (1989), 1148.

9) T. Ando, S. Shimamoto, T. Hiyama, H. Tsuji, Y. Takahashi, M. Nishi, K. Yoshida, E. Tada, K. Okuno, K. Koizumi, T. Kato, H. Nakajima, L. Dresner, F. Iida, Y. Sanada, M. Shimada, O. Takahashi and K. Yasukochi: IEEE Trans. Magn., MAG-19 (1983), 312.

10) J. W. Ekin: Cryogenics, 20 (1980), 611.

11) J. A. Shepic: Materials Studies for Magnetic Fusion Energy Applications at Low Temperatures-II, NBSIR 791609, Nat. Bur. Standards, Boulder, CO, (1979), 35.

12) H. Nakajima, K. Yoshida, S. Shimamoto, R. L. Tobler, P. T. Purtscher and R. P. Reed: Advances in Cryogenic Engineering Materials, Vol. 34, Plenum Press, New York, (1988), 241

13) H. Nakajima, K. Yoshida, S. Shimamoto, R. L. Tobler and R. P. Reed: Advances in Cryogenic Engineering Materials, Vol. 36, Plenum Press, New York, (1990), 1069.

14) H. Nakajima, K. Yoshida and S. Shimamoto: Cryo. Eng., 21 (1986), 197.

15) T. Horiuchi, M. Shimada, T. Fukutsuka and S. Tokuda: Proc. the Fifth Int. Cryogenic Engineering Conf., MidCountry Press, London, (1974).

16) H. Nakajima, K. Yoshida, K. Okuno, M. Oshikiri, E. Tada, S. Shimamoto, R. Miura, M. Shimada, S. Tone, K. Suemune, T. Sakamoto and K. Nohara: Advances in Cryogenic Engineering Materials, Vol. 32, Plenum Press, New York, (1986), 347.

17) H. Nakajima, K. Yoshida, Y. Takahashi, E. Tada, M. Oshikiri, K. Koizumi, S. Shimamoto, R. Miura, M. Shimada, S. Tone, H. Masumoto and T. Sakamoto: Advances in Cryogenic Engineering Materials, Vol. 30, Plenum Press, New York, (1984), 219.

18) R. L. Tobler and R. P. Reed: Materials Studies for Magnetic Fusion Energy Applications at Low TemperaturesIII, NBSIR 80-1627, Nat. Bur. Standards, Boulder, CO, (1979), 17.

19) D. T. Read and R. P. Reed: Materials Studies for Magnetic Fusion Energy Applications at Low Temperatures, II, NBSIR 79-1609, Nat. Bur. Standards, Boulder, CO, (1979), 81.

20) T. Sakamoto, Y. Nakagawa, I. Yamauchi, T. Zaizen, H. Nakajima and S. Shimamoto: Advances in Cryogenic Engineering Materials, Vol. 30, Plenum Press, New York, (1984), 137. 
21) K. Suemune, T. Sakamoto, T. Ogawa, T. Okazaki, S. Maehara, H. Nakajima and S. Shimamoto: Advances in Cryogenic Engineering Materials, Vol. 34, Plenum Press, New York, (1988), 123.

22) K. Nohara M. Shimotomai and Y. Habu: J. Nuclear Mater., 169 (1989), 264.

23) H. Masumoto, K. Suemune, H. Nakajima and S. Shimamoto: Advances in Cryogenic Engineering Materials, Vol. 30, Plenum Press, New York, (1984), 169.

24) K. Suemune, K. Sugino, H. Masumoto, H. Nakajima and S. Shimamoto: Advances in Cryogenic Engineering Materials, Vol. 32, Plenum Press, New York, (1986), 51.

25) S. Tone, M. Shimada, T. Horiuchi, Y. Kasamatsu, H. Nakajima and S. Shimamoto: Advances in Gryogenic Engineering Materials, Vol. 30, Plenum Press, New York, (1984), 145.

26) J. Ishizaka, R. Miura, H. Nakajima and S. Shimamoto: Tetsu-to-Hagané, 76 (1990), 791.

27) S. Shimamoto, H. Nakajima, K. Yoshida and E. Tada: Advances in Cryogenic Engineering Materails, Vol. 32, Plenum Press, New York (1986), 23.

28) S. Tone, M. Hiromatsu, J. Numata, T. Horiuchi, H. Nakajima and S. Shimamoto: Advances in Cryogenic Engineering Materials, Vol. 32, Plenum Press, New York, (1986), 89.
29) T. Ogawa, T. Koseki, S. Ohkita and H. Nakajima; Weld. J., 69 (1990), No. 6, 205s

30) K. Yoshida, H. Nakajima, M. Oshikiri, R. L. Tobler, S. Shimamoto, R. Miura and J. Ishizaka: Advances in Cryogenic Engineering Materials, Vol. 34, Plenum Press, New York, (1988), 225.

31) H. Nakajima, K. Yoshida, M. Oshikiri, Y. Takahashi, K. Koizumi, S. Shimamoto, M. Shimada, S. Tone, S. Sakamoto, K. Suemune and K. Nohara: Advances in Cryogenic Engineering Materials, Vol. 34, Plenum Press, New York, (1988), 173.

32) M. Shimada and S. Tone: Advances in Cryogenic Engineering Materials, Vol. 34, Plenum Press, New York, (1988), 131.

33) H. Tsuji, K. Okuno, H. Nakajima, T. Ando, Y. Takahashi, M. Nishi, K. Yoshida, E. Tada, K. Koizumi, T. Kato, T. Isono, M. Oshikiri, T. Hiyama, K. Kawano, H. Yamamura, M. Sato, J. Yoshida, N. Itoh, and S. Shimamoto: IEEE Trans. Magn., MAG-25 (1989), 1484.

34) H. Nakajima, K. Okuno, H. Tsuji, K. Yoshida, K. Koizumi, T. Isono, E. Yaguchi, H. Shimane and S. Shimamoto: Proc. of 11 th Int. Conf. on Magnet Technology, Elsevier Sci. Publ., Ltd., London, (1990), 824. 